\title{
Mimicking mother nature: The Valsalva graft
}

Ruggero De Paulis, MD, ${ }^{\mathrm{a}, \mathrm{b}}$ Raffaele Scaffa, MD, ${ }^{\mathrm{a}}$ Luca Weltert, $\mathrm{MD},{ }^{\mathrm{a}}$ and Andrea Salica, MD

From the ${ }^{\mathrm{a} D e p a r t m e n t}$ of Cardiac Surgery, European Hospital, Rome, Italy; and ${ }^{\mathrm{b}}$ Department of Cardiothoracic Surgery, Weill Cornell Medicine, New York, NY.

Received for publication March 31, 2019; revisions received June 3, 2019; accepted for publication June 8, 2019; available ahead of print Oct 21, 2019

Address for reprints: Ruggero De Paulis, MD, Department of Cardiac Surgery, European Hospital, Via Portuense 700, 00149 Rome, Italy (E-mail: rdepaulis58@gmail.com).

J Thorac Cardiovasc Surg 2020;159:1758-63

$0022-5223 / \$ 36.00$

Copyright (c) 2019 Published by Elsevier Inc. on behalf of The American Association for Thoracic Surgery

https://doi.org/10.1016/j.jtcvs.2019.06.128

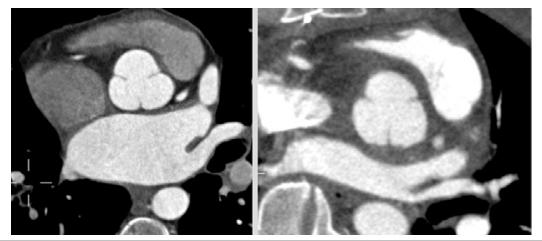

A normal aortic root compared with an aortic valve reimplanted into a Valsalva graft.

\section{Central Message}

A few key steps are necessary for a correct aortic valve reimplantation into a Valsalva conduit. After the procedure the original spherical shape of the graft changes into a trilobate morphology.

See Commentary on page 1764.
When the Valsalva graft (Terumo Aortic, Renfrewshire, United Kingdom) was first conceived and designed more than 20 years ago, the goal was to find a method to easily recreate neosinuses of Valsalva after a valve-sparing root reimplantation procedure. However, given the simple design and intrinsic characteristics of this novel solution, it was also advantageous to use when performing remodeling or Bentall procedures. In fact, in the very first article on this novel Dacron (DuPont, Wilmington, De) aortic graft, the initial clinical results in all 3 types of aortic root surgery were presented.

During subsequent years, this graft has been extensively used in both the Bentall, and the reimplantation procedure. However, those who have continued to champion the remodeling procedure have also adopted the use of the Valsalva graft with outstanding results to date. ${ }^{2}$ As for the Bentall procedure, the major mechanical heart valve companies have progressively adopted this peculiar graft morphology in manufacturing their valve conduits. When used in the Bentall operation particularly, the benefit of this type of graft design has been demonstrated in reducing the stress at the coronary anastomosis ${ }^{3}$ and in regulating coronary blood flow ${ }^{4}$ without compromising or affecting normal prosthetic leaflet motion.

During recent years, the benefits of a valve-sparing procedure have become increasingly evident and, over time, a growing number of these operations have been performed on a regular basis. Given the improved mid- and long-term clinical results ${ }^{6}$ and the excellent hemostatic characteristics, the reimplantation procedure is now the most frequently performed type of valve-sparing operation.

Modifications of the original technique, as described in 1992 by David and Feindel, ${ }^{7}$ have been mainly aimed at some sort of neosinuses reconstruction either by modifying a larger diameter straight graft or by using specifically designed prefabricated grafts, such as the Valsalva graft. The benefit of having sinuses when replacing the aortic root has been clearly demonstrated. ${ }^{8}$ The presence of sinuses guarantees proper and physiologic aortic leaflet motion during both the opening and closing phases. This finding was demonstrated in patients after both a remodeling $^{9}$ or a reimplantation procedure with the Valsalva graft, in which postoperative echocardiography showed near normal aortic valve opening and closing characteristics. ${ }^{10}$ In fact, the presence of sinuses favors the formation of eddy currents that are of paramount importance in regulating a smooth, progressive, symmetric, synchronous and stress-free leaflet closure (Video 1 and 2). Furthermore, in a more recent in vitro study, the presence of sinuses was shown to be important to guarantee proper and complete valve opening. In a cylindrical conduit without sinuses, the systolic blood flow causes turbulence around the leaflets that reduces their effective orifice area. ${ }^{11}$ This finding was further confirmed in a study showing continuous steady flow becoming turbulent in a straight tube configuration. ${ }^{12}$ Both studies were instrumental to show how the presence of sinuses immediately distal to the aortic valve allows 


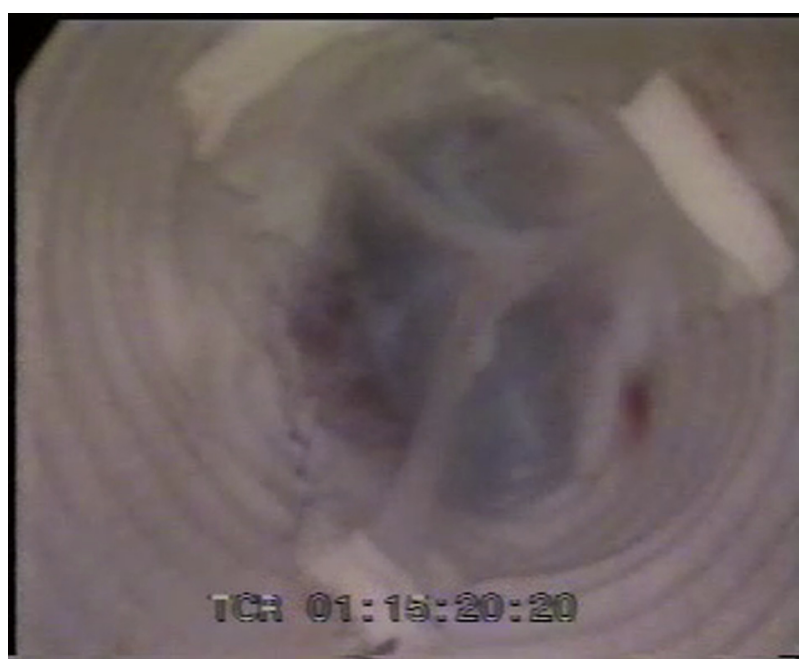

VIDEO 1. Endoscopic direct view of an aortic valve reimplanted into a straight Dacron (DuPont, Wilmington, De) conduit. No sinuses are present but there is no contact of the leaflet with the Dacron wall. There is no symmetric valve closure and there is no synchrony in the closure of the three cusps. During the opening and closing phases the leaflet-free margin present folds and wrinkles as an effect of high velocity, turbulent flow. Video available at: https://www.jtcvs.org/article/S0022-5223(19)31821-5/ fulltext.

full valve opening, which is especially evident when blood flow is increased during effort.

Despite a wealth of physiologic evidence, there is still no strong clinical evidence that the presence of sinuses significantly impacts valve durability. Good long-term results have been reported after using both straight and Valsalva conduits. ${ }^{13-16}$ It is possible that the aortic valve has the capacity to adapt to physiologic changes or that longer follow-up is necessary for any differences to become evident. Nonetheless, it is very important to emphasize that optimal long-term results, the need for reoperation, and the incidence of residual aortic valve regurgitation after a reimplantation procedure are influenced by many factors. The use of a straight conduit or a conduit with sinuses, such as the Valsalva graft, is only a single factor and certainly it is not the most important. Without question, the technique used to reimplant the valve inside the Dacron conduit, the way the commissures are positioned geometrically in relation to one another under the right amount of tension-or put more succinctly, the way the valve is properly and geometrically repositioned inside the conduit-is far more important for the long-term success of the operation. Another fundamental component is the proper treatment of leaflet prolapse, whether preexisting or induced by the reduction in root diameter that is a necessary step of the operation. For all the above reasons, it is evident that no conduit can compensate for a suboptimal surgical

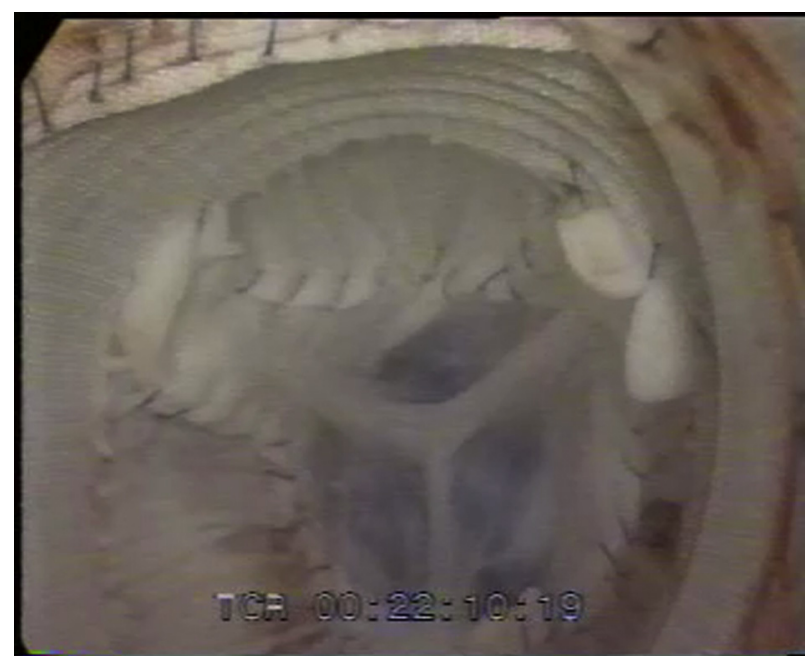

VIDEO 2. Endoscopic direct view of an aortic valve reimplanted into a Valsalva Dacron (DuPont, Wilmington, De) conduit. Three independent reconstructed sinuses are clearly evident. The different position of the commissural posts in respect to the bulging sinuses is also clear. Leaflet movements during valve closure appear smooth, symmetric and synchronous. The leaflet-free margin appears always distended during the whole cardiac cycle testifying the presence of low velocity eddy currents inside the sinuses. Video available at: https://www.jtcvs.org/article/S00225223(19)31821-5/fulltext.

performance in reimplanting the aortic valve. Nevertheless, some basics of the technique need to be respected, especially when using the Valsalva graft to achieve an optimal root reconstruction.

In a recent experimental study aimed at comparing straight and Valsalva conduits, Paulsen and colleagues ${ }^{17}$ concluded that the use of a Valsalva graft failed to maintain the commissures in their native cylindrical formation, resulting in negative consequences in terms of leaflet coaptation, opening velocities, leaflet forces, and regurgitant fraction. However, on careful review of the root reconstruction used by the authors in the experiments, it is more likely that the suboptimal results are secondary to incorrect positioning of the commissures within the Valsalva graft. If the commissures are not positioned at the level of the new sinotubular (ST) junction to ensure conditions that properly restore the skeleton of the root, suboptimal results are to be expected. The present work provides an opportunity to clarify some essential technical considerations that make the use of the Valsalva graft different from a standard straight Dacron graft.

The Valsalva graft has 2 main sections: a straight portion with horizontal pleats representing the tubular ascending aorta; and a bulged portion, called the skirt, with vertical pleats representing the aortic root. The thicker suture connecting these 2 portions corresponds to the new ST junction. There is a third short tubular portion below the skirt, called the collar, that is only used for attaching an aortic valve prosthesis when performing a Bentall procedure. However, 


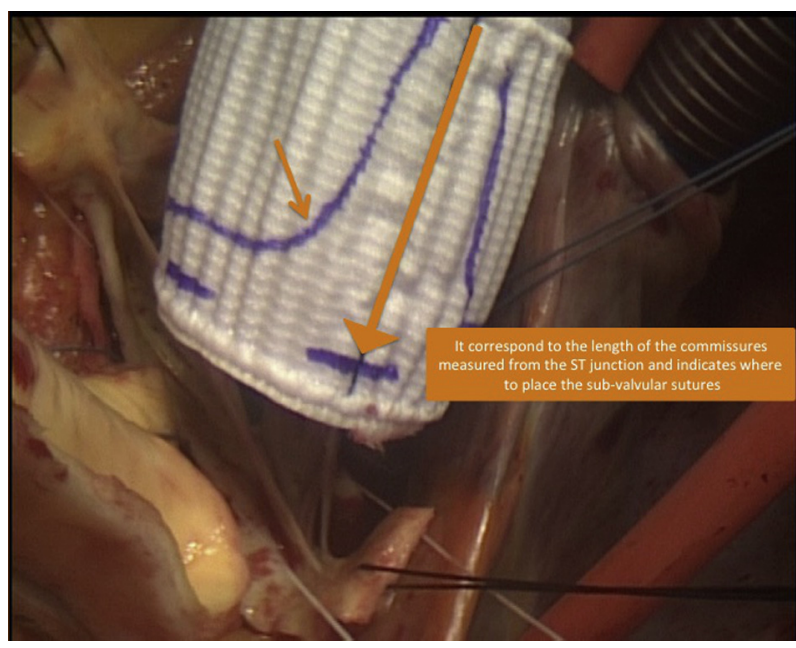

FIGURE 1. The length of the commissural posts are measured and compared with the skirt of the graft from the sinotubular junction down toward the base of the skirt. This point is marked (big arrow) to indicate the proper level where the annular sutures need to be placed along the whole circumference. This will ensure that once the commissural posts are stretched they will easily reach the sinotubular junction where they will be anchored. Another curved line (small arrow) in the shape of the sinuses can also be used as a suturing path to simplify the fixing of valve remnants to the Dacron (DuPont, Wilmington, De) graft. ST, Sinotubular. Image from reference 19. Used with permission.

when a Valsalva graft is used for a reimplantation procedure the collar is not necessary and should be removed. An important point is that the skirt of the graft has a height that is equal to the diameter of the graft. This is more length that is normally needed but it gives the freedom to adapt it to different anatomic sizes of aortic leaflets and commissures.

The operation starts by isolating the coronary buttons on a Carrel patch and excising the dilated sinuses. The root is dissected deep down to the annulus. A complete root dissection is important because it allows the Dacron conduit to completely encompass the aortic valve. Although usually possible, sometimes a deep dissection can be difficult at the level of the right coronary sinus. Conversely, at the level of the left and right commissure it is always possible to reach the level of the annulus by breaking the fibrous tissue connecting the aortic wall to the pulmonary trunk. A series of pledgeted U-stitches are then passed inside out in the left ventricular outflow tract along a line connecting the nadirs of each aortic cusp, namely the virtual basal ring. In rare cases a complete horizontal dissection is difficult on the right sinus, in which case slightly oblique stitches are still efficient. The annulus is loosely sized with a Hegar dilator and a Valsalva graft $5 \mathrm{~mm}$ larger than the annulus is selected. The $5 \mathrm{~mm}$ difference accounts for the thickness of the aortic wall because the Dacron graft is placed on the outside of the root. When the annulus is $27 \mathrm{~mm}$ or larger a 32-mm Valsalva graft is always chosen. At this point, the graft needs to be secured to the annular sutures. The level at which to position the sutures inside the skirt is probably the most important individual point for the correct use of a Valsalva graft. Simply securing the very bottom of the skirt to the annulus will often result in the inability of the top of the commissure to reach the level of the ST junction. Most of the time, the height of the skirt is greater than the height of the commissures. It is therefore necessary to measure the height of the commissure from the pledgets placed at the base of interleaflet triangles (along the line connecting the nadirs of the cusps) up to the top of the commissure. Once this length has been determined (usually between 23 and $25 \mathrm{~mm}$ ), the same distance is marked on the skirt of the graft starting from the ST junction down to define the proper level to pass the annular sutures (see Figure 1). ${ }^{18}$ With the use of a pen the level of the annular suture is marked circumferentially and the annular sutures are then
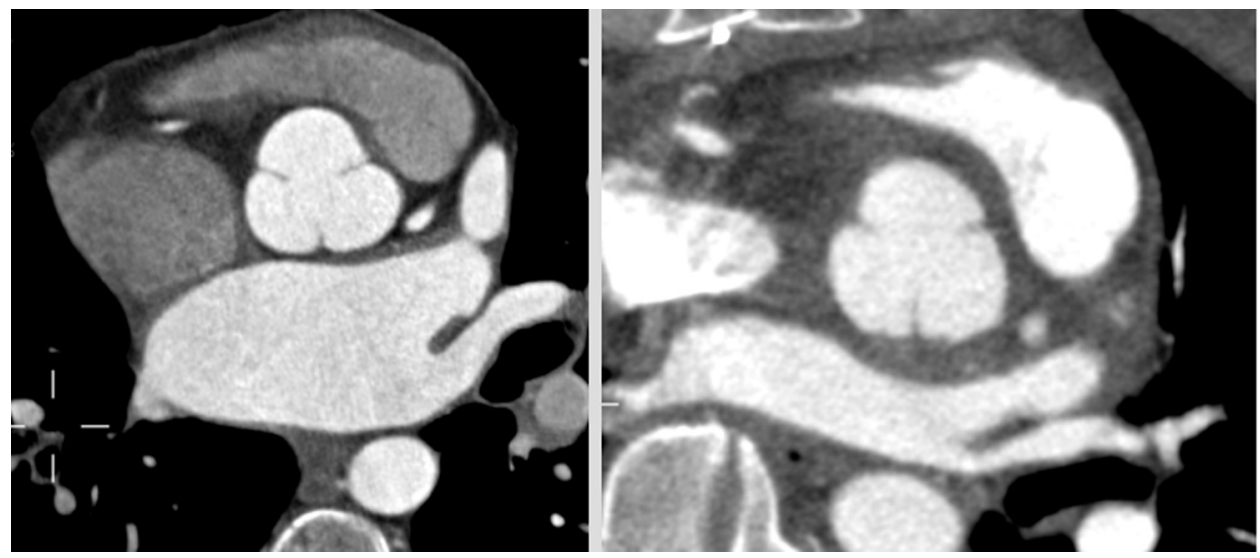

FIGURE 2. Postoperative computed tomography scans of a normal individual (left) and of a patient after a reimplantation type of valve-sparing procedure using the Valsalva graft (right). The short-axis view clearly shows similar trilobate aspect of the root. It is evident that the Valsalva graft has prevented any radial displacement of the commissural posts. Only 3 independent sinuses bulge out. 

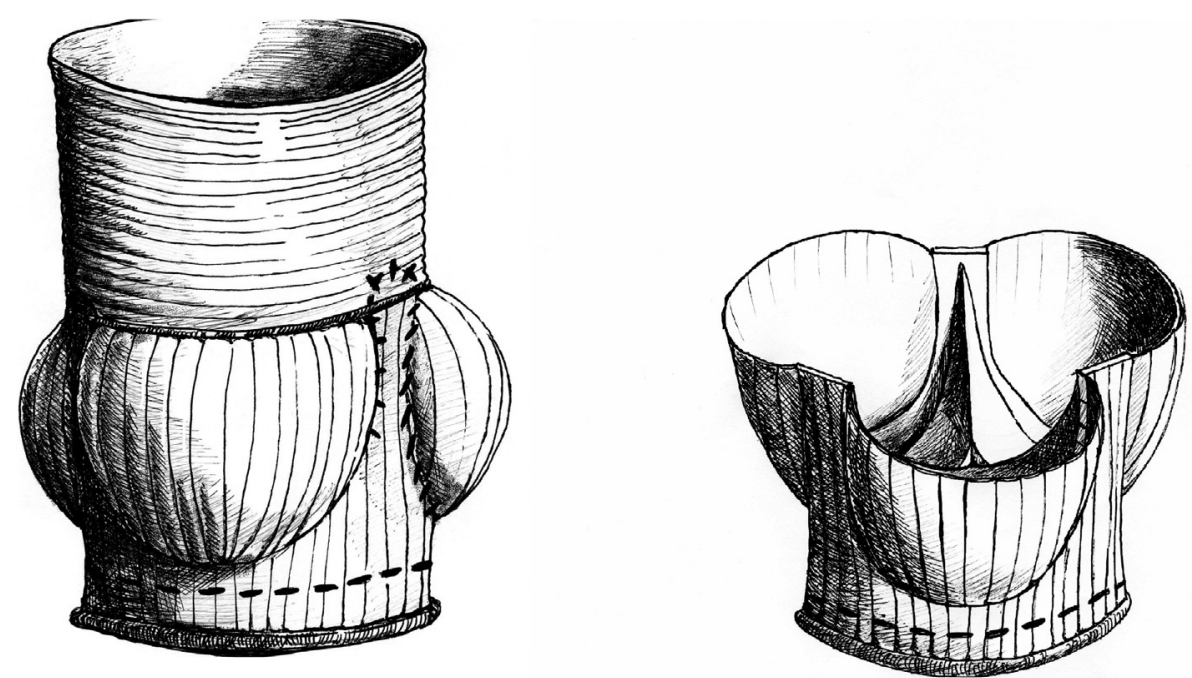

FIGURE 3. Sketch of a classic reimplantation procedure correctly performed with the Valsalva graft (left). The commissural posts are stretched between a lower fixed ring (the annulus) and another cylindrical fixed ring (the sinotubular junction). At this point the skeleton of the aortic valve is already in its cylindrical straight position. After the valve remnants are then sutured to the skirt of the Dacron (DuPont, Wilmington, De) graft the pressurized portion of the Dacron graft (the neosinuses) will bulge out, whereas the nonpressurized portion of the Dacron graft (beyond the commissural posts) will remain adherent to the commissures. The inside sketch of the graft (right) highlights the different spatial relationship of the commissures and the sinuses that are necessary to reproduce the trilobate aspect of the root. The Valsalva graft changes its original spherical shape into a trilobate shape after the valve is correctly positioned and sutured inside. Image from reference 18 . Used with permission.

passed through at this level. For example, when using a 30$\mathrm{mm}$ graft with a commissure length of $25 \mathrm{~mm}$, the annular sutures are passed $5 \mathrm{~mm}$ higher than the base of the skirt ( $25 \mathrm{~mm}$ below the level of the new ST junction). Once the graft is securely anchored to the annulus, the excess skirt will lie naturally at the base of the root and does not need to be excised. Anchoring the graft will produce a strong annuloplasty effect with a reduction of the original annular
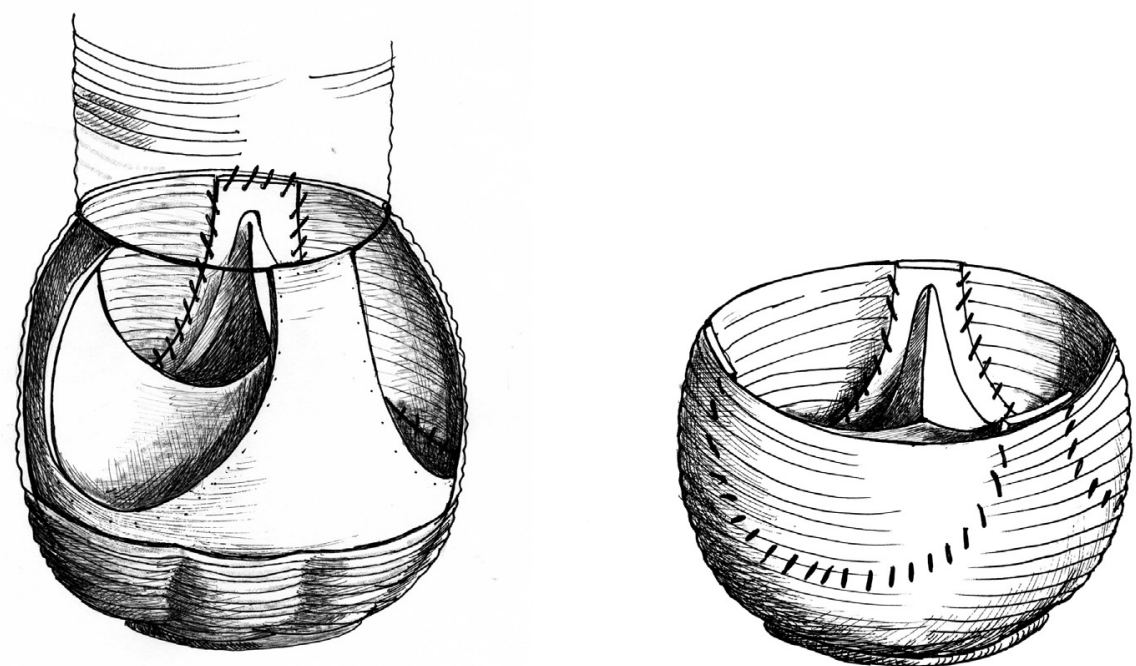

FIGURE 4. We propose a sketch of a straight Dacron (DuPont, Wilmington, De) graft with a reimplanted aortic valve (right). Only if the diameter of the graft is equal to the diameter of the aortic valve, will the commissural post be in the natural straight position. If the straight Dacron graft is larger (as often is the case to prevent the leaflet making contact with the Dacron wall and creating some sort of neosinuses), the commissural posts are forced into a curved and arched position. Furthermore, the radius of curvature passing along the commissures is the same as passing along the sinuses. The final result is that is impossible to reproduce the trilobate aspect of the aortic root (right). Image from reference 18. Used with permission. 
diameter. Depending on surgeon preferences, the basal ring sutures can the tied around a Hegar dilator of a proper size. At this point the commissures need to be retrieved from inside of the graft and positioned at the level of the new ST junction. The commissures are gently stretched in a straight position and fixed right above the new ST junction (ie, the line connecting the skirt of the graft with the cylindrical straight portion). It is very important to understand this step because this maneuver is essential for optimal reconstruction of the skeleton of the aortic valve. In fact the commissural posts are now stretched between 2 rings: the lower ring represented by the annulus and the upper ring represented by the cylindrical fixed diameter of the ST junction. By connecting these 2 nondeformable and fixed rings, the 3 commissural posts act as the 3 pillars that are needed to keep the natural cylindrical valve geometry. Next, following the standard technique, the crown-shaped valve remnants are sutured to the skirt of the Valsalva graft. Usually, simply sketching with a pen the shapes of the sinus onto the graft provides a reference that helps in accurate suturing of the valve remnants. Once this is complete, the shape of the Valsalva graft will change completely. Only the portion of Dacron between 2 commissural posts will be able to bulge out, making 3 independent sinuses, whereas the portion of graft behind the commissures (not in contact with the bloodstream) will be adherent to the 3 commissural posts in their cylindrical straight position. This will perfectly replicate the trilobed native root geometry when visualized in short axis (Figure 2). In summary, after the valve is reimplanted, the Valsalva graft is no longer spherical; it conforms to the reconstructed skeleton of the aortic valve (Figures 3 and 4). ${ }^{19}$ Representing the Valsalva graft in the absence of the sutures needed to reimplant the aortic valve is misleading. The procedure-related steps outlined in this review, completely change the final conformation and shape of the Valsalva graft. Its initial spherical shape is changed into a trilobate profile because the aortic valve commissural posts are strongly anchored between 2 fixed rings.

Because of its intrinsic characteristics, the Valsalva graft is perfectly suited also to reimplant bicuspid valves. After the procedure is completed the graft will change its shape in the form of 2 large, independent sinuses. The procedure steps are virtually identical. In the presence of a raphe, it is important to suture it at the bottom of the sinus to avoid undue tension that would negatively influence closure of the valve.

Once the valve has been properly reimplanted, the operation is concluded without any variations in the standard procedure by adding a leaflet plication where necessary, reattaching the coronary button, and then performing the aortic distal anastomosis.

The perfect and anatomic reconstruction of the root using the Valsalva graft with normalization of the blood flow inside the reconstructed sinuses has recently been further confirmed by the use of 4-dimensional magnetic resonance imaging as part of a series of studies on behalf of the Cornell International Consortium for Aortic Surgery. ${ }^{20}$

\section{CONCLUSIONS}

The benefit of the Valsalva graft in achieving a good anatomic root reconstruction with physiologic blood flow and normal aortic valve function can only be achieved using proper technique. Failing to follow the key steps of this operation will invariably lead to suboptimal results.

\section{Conflict of Interest Statement}

Dr De Paulis, the inventor and designer of the Valsalva graft, receives royalties from Terumo Aortic. All other authors have nothing to disclose with regard to commercial support.

\section{References}

1. De Paulis R, De Matteis GM, Nardi P, Scaffa R, Colella DF, Chiarello L. A new aortic Dacron conduit for surgical treatment of aortic root pathology. Ital Heart J. 2000; 1:457-63.

2. Lansac E, Di Centa I, Sleilaty G, Lejeune S, Berrebi A, Zacek P, et al. Remodeling root repair with an external aortic ring annuloplasty. J Thorac Cardiovasc Surg. 2017; 153:1033-42.

3. Weltert L, De Paulis R, Scaffa R, Maselli D, Bellisario A, D'Alessandro S. Recreation of a sinuslike graft expansion in Bentall procedure reduces stress at the coronary button anastomoses: a finite element study. J Thorac Cardiovasc Surg. 2009;137:1082-7.

4. De Paulis R, Tomai F, Bertoldo F, Ghini AS, Scaffa R, Nardi P, et al. Coronary flow characteristics after a Bentall procedure with or without sinuses of Valsalva. Eur J Cardiothorac Surg. 2004;26:66-72.

5. De Paulis R, Schmitz C, Scaffa R, Nardi P, Chiariello L, Reul H. In vitro evaluation of aortic valve prosthesis in a novel valved conduit with pseudosinuses of Valsalva. J Thorac Cardiovasc Surg. 2005;130:1016-21.

6. David TE, Feindel CM, David CM, Manlhiot C. A quarter of a century of experience with aortic valve-sparing operations. J Thorac Cardiovasc Surg. 2014; 148: $872-9$.

7. David TE, Feindel CM. An aortic valve-sparing operation for patients with aortic incompetence and aneurysm of the ascending aorta. J Thorac Cardiovasc Surg. 1992;103:617-21.

8. Grande-Allen KJ, Cochran RP, Reinhall PG, Kunzelman KS. Recreation of sinus is important for sparing the aortic valve: a finite element study. J Thorac Cardiovasc Surg. 2000;119:753-63.

9. De Paulis R, De Matteis GM, Nardi P, Scaffa R, Buratta MM, Chiariello L. Opening and closing characteristics of the aortic valve after valve-sparing procedures using a new aortic root conduit. Ann Thorac Surg. 2001;72: 487-94

10. De Paulis R, De Matteis GM, Nardi P, Scaffa R, Bassano C, Chiariello L. Analysis of valve motion after the reimplantation type of valve-sparing procedure (David I) with a new aortic root conduit. Ann Thorac Surg. 2002;74 $53-7$.

11. Pisani G, Scaffa R, Ieropoli O, Dell'Amico EM, Maselli D, Morbiducci U, et al Role of the sinuses of Valsalva on the opening of the aortic valve. J Thorac Car diovasc Surg. 2013;145:999-1003.

12. Salica A, Pisani G, Morbiducci U, Scaffa R, Massai D, Audenino A, et al. The combined role of sinuses of Valsalva and flow pulsatility improves energy loss of the aortic valve. Eur J Cardiothorac Surg. 2016;49:1222-7.

13. De Paulis R, Chirichilli I, Scaffa R, Weltert L, Maselli D, Salica A, et al. Longterm results of the valve reimplantation technique using a graft with sinuses. $J$ Thorac Cardiovasc Surg. 2016;151:112-9.

14. David TE, David CM, Feindel CM, Manlhiot C. Reimplantation of the aortic valve at 20 years. J Thorac Cardiovasc Surg. 2017;153:232-8. 
15. Shrestha ML, Beckmann E, Abd Alhadi F, Krueger H, Meyer-Bockenkamp F, Bertele S, et al. Elective David I procedure has excellent long-term results: 20year single-center experience. Ann Thorac Surg. 2018;105:731-8.

16. Mastrobuoni S, de Kerchove L, Navarra E, Watremez C, Vancraeynest D, Rubay J, et al. Long-term experience with valve-sparing reimplantation technique for the treatment of aortic aneurysm and aortic regurgitation. J Thorac Cardiovasc Surg. 2019;158:14-23.

17. Paulsen MJ, Kasinpila P, Imbrie-Moore AM, Wang H, Hironaka CE, Koyano TK, et al. Modeling conduit choice for valve-sparing aortic root replacement on biomechanics with a 3-dimensional-printed heart simulator. J Thorac Cardiovasc Surg. 2019;158:392-403.

18. De Paulis R. PRO-CON debate: valve sparing root surgery. PRO: reimplantation. Gen Thorac Cardiovasc Surg. 2019;67:77-81.

19. De Paulis R, Scaffa R. Perspective. Valve sparing root repair. Tips and tricks. In dian J Thorac Cardiovasc Surg. 2019;35(Suppl 2):92-5.

20. Gaudino M, Piatti F, Lau C, Sturla F, Weinsaft JW, Welter L, et al. Aortic flow after valve sparing root replacement with or without neosinuses reconstruction. J Thorac Cardiovasc Surg. 2019;157:455-65. 